\title{
Geschichte der Vereinigten Staaten von Amerika
}

von

Otto Graf zu Stolberg-Wernigerode

2. neubearbeitete Auflage

Mit einem besonderen Beitrag

Die amerikanische Wirtschaft

seit der industriellen Revolution

von

Hans Jaeger

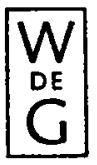

Sammlung Göschen Band 7005

Walter de Gruyter

Berlin · New York · 1973 


\section{Dr. phil. Otto Graf zu Stolberg-Wernigerode ist em. o. ö. Professor für europäische Geschichte an der Universität München \\ Dr. phil. Hans Jaeger \\ ist Lehrbeauftragter für Unternehmensgeschichte \\ an der Universität München}

\section{ISBN 3110043645}

\section{(C)}

Copyright 1973 by Walter de Gruyter \& Co., vormals G. J. Gōschen'sche Verlagshandlung, J. Guttentag, Vetlagsbuchhandlung, Georg Reimer, Karl J. Trübner, Veit \& Comp., 1 Berlin 30.

Alle Rechte, insbesondere das Recht der Vervielfältigung und Verbreitung sowie der Übersetzung, vorbehalten. Kein Teil des Werkes darf in irgendeiner Form (durch Fotokopie, Mikrofilm oder ein anderes Verfahren) ohne schriftliche Genehmigung des Verlages reproduziert oder unter Verwendung elcktronischer Systeme verarbeitet, vervielfältigt oder verbrcitet werden.

$$
\text { Printed in Germany. }
$$

Satz und Druck: Saladruck, 1 Berlin 36. 